\title{
Improved $\beta$-cell function rather than increased insulin sensitivity is associated with reduction in hemoglobin A1c in newly diagnosed Type 2 diabetic patients treated with metformin
}

\author{
Satoru Sumitani ${ }^{1,2^{\star}}$, Shinya Morita ${ }^{2}$, Reiko Deguchi ${ }^{2}$, Koichi Hirai ${ }^{2}$, Kosuke Mukai ${ }^{2}$, \\ Yoshihiko Utsu' ${ }^{2}$, Shunji Miki ${ }^{2}$, Bunzo Sato ${ }^{2}$, Hideji Nakamura $^{1}$, Soji Kasayama ${ }^{2}$ \\ ${ }^{1}$ Center for Preventive Medicine, Nissay Hospital, Osaka, Japan; ${ }^{*}$ Corresponding Author: sa_sumitani@yahoo.co.jp \\ ${ }^{2}$ Department of Medicine, Nissay Hospital, Osaka, Japan
}

Received 28 December 2013; revised 25 January 2014; accepted 3 February 2014

Copyright (C) 2014 Satoru Sumitani et al. This is an open access article distributed under the Creative Commons Attribution License, which permits unrestricted use, distribution, and reproduction in any medium, provided the original work is properly cited. In accordance of the Creative Commons Attribution License all Copyrights @ 2014 are reserved for SCIRP and the owner of the intellectual property Satoru Sumitani et al. All Copyright (C) 2014 are guarded by law and by SCIRP as a guardian.

\section{ABSTRACT}

$\beta$-cell dysfunction and decreased insulin sensitivity are believed to be two chief mechanisms that participate in deterioration of glycemic control in Type 2 diabetes. Meformin is widely accepted as the first-line oral agent in the treatment of Type 2 diabetes. However, the relative contributions of improved $\beta$-cell function and increased insulin sensitivity to reduction in hemoglobin A1c (HbA1c) are unclear in newly diagnosed Type 2 diabetic patients treated with metformin. We investigated $\beta$-cell function and insulin sensitivity in relation to reduction in HbA1c in 20 newly diagnosed Type 2 diabetic patients (17 men and 3 women, mean age $49.1 \pm$ 10.1 years, mean body mass index $26.4 \pm 5.2$ $\mathrm{kg} / \mathrm{m}^{2}$ ) treated with metformin for 16 weeks. We used homeostasis model assessment (HOMA) $2 \% B$ and HOMA2\%S as estimates of $\beta$-cell function and insulin sensitivity, respectively. Median HOMA2\%B and HOMA2\%S significantly increased from 38.8 to $68.8(p<0.001)$ and from 50.2 to $67.1(p=0.004)$, respectively. In univariate regression analysis, reduction in HbA1c was highly correlated with change in HOMA2\%B $(r=-0.866, p<0.001)$, but not with that in HOMA2\%S $(r=-0.264, p=0.260)$. Furthermore, multivariate regression analysis with reduction in $\mathrm{HbA1c}$ as a dependent variable showed that increase in HOMA2\%B but not that in HOMA2\%S was a significant dependent variable $(\beta=-0.847$, $p<0.001)$. In conclusion, our findings demonstrate that improved $\beta$-cell function rather than increased insulin sensitivity is associated with reduction in HbA1c. These results suggest that metformin reduces $\mathrm{HbA1c}$ chiefly through improved $\beta$-cell function rather than increased insulin sensitivity in patients with newly diagnosed Type 2 diabetes.

\section{KEYWORDS}

Metformin; Type 2 Diabetes; $\beta$-Cell Function; Insulin Sensitivity

\section{INTRODUCTION}

Early and aggressive glycemic control to achieve nearnormal glycemia is essential to prevent late vascular complications in patients with Type 2 diabetes. The United Kingdom Prospective Diabetes Study (UKPDS) 34 showed that metformin reduces the risk of diabetesrelated endpoints, myocardial infarction, diabetes-related death and all-cause mortality in patients with newly diagnosed Type 2 diabetes [1]. Moreover, UKPDS7 showed that only 482 patients among 3044 patients (15.8\%) achieved near-normal fasting plasma glucose (FPG) less than $6.0 \mathrm{mmol} / \mathrm{l}$ after the initial 3 months' diet in the run-in phase, suggesting that most patients with newly diagnosed Type 2 diabetes fail to achieve near-normal FPG by diet alone in a routine clinical setting [2]. Therefore, the treatment guidelines for an initial management of hyperglycemia in patients with Type 2 state that met- 
formin and lifestyle interventions should be started at the time of diagnosis [3,4]. Indeed, we previously demonstrated that metformin and lifestyle interventions are effective and safe as an initial management of hyperglycemia in Japanese patients with newly diagnosed Type 2 diabetes [5].

A progressive decline in $\beta$-cell function is the major determinant of loss of glycemic control over time in Type 2 diabetic patients [6,7]. Hyperglycemia in patients with Type 2 diabetes, however, is caused by impaired peripheral insulin sensitivity, which results in decreased insulin-mediated glucose disposal; increased endogenous glucose production, chiefly from the liver; and inadequate pancreatic insulin secretion [8]. However, the relative contribution of $\beta$-cell function and insulin sensitivity to glucose-lowering effects of metformin in patients with newly diagnosed Type 2 diabetes is unclear.

In the present study, we aimed to examine the relative contribution of $\beta$-cell function and insulin sensitivity to reduction in hemoglobin A1c (HbA1c) in newly diagnosed Type 2 diabetic patients treated with metformin.

\section{MATERIALS AND METHODS}

\subsection{Study Design and Patients}

The present study is a retrospective analysis of EMINENT (Effectiveness of metformin and lifestyle interventions as an initial treatment in Japanese patients with newly diagnosed Type 2 diabetes) Study, which was a prospective observational study within a routine clinical setting to examine the effectiveness of metformin and lifestyle interventions as an initial treatment in Japanese patients with newly diagnosed Type 2 diabetes. The details of EMINENT study were reported elsewhere [5]. Briefly, eligible patients were newly diagnosed patients with Type 2 diabetes aged 20 - 75 years with HbA1c levels $\geq 6.5 \%$, and who had never taken an oral hypoglycemic agent. The diagnosis of Type 2 diabetes was made on the WHO 1999 criteria [9]. Metformin and lifestyle interventions were started at the time of diagnosis and the dose of metformin was titrated to $1500 \mathrm{mg} /$ day or maximum-tolerated dose. Lifestyle interventions were composed of an individualized dietary counseling and an encouragement to increase daily physical activities. The primary outcomes were reduction in HbA1c and the proportion of patients who achieved HbA1c $<7.0 \%$ after 16 weeks. The study was conducted in accordance with the Declaration of Helsinki and with the approval of the local ethics committee. Each patient provided written informed consent for study participation and the use of their data for research purposes. In the present study, we analyzed the data from 20 patients who had measurements of fasting serum C-peptide at the baseline and after 16 weeks.

\subsection{Laboratory Analysis}

Plasma glucose was determined using the hexokinase, glucose-6-phosphate dehydrogenase method. HbA1c was measured with HLC-723G8 (Tosoh Co., Tokyo, Japan) by high performance liquid chromatography (HPLC) approved by the National Glycohemoglobin Standardization Program [10]. Serum C-peptide was measured by chemiluminescent enzyme immunoassays (FUJIREBIO Inc., Tokyo, Japan), with an interassay coefficient of variation of $4.1 \%$ and an intraassay coefficient of variation of 3.4\%. Total cholesterol, triglyceride, and highdensity lipoprotein cholesterol (HDL-C) were measured using standard laboratory methods. Low-density lipoprotein cholesterol (LDL-C) was calculated by Friedewald equation [11]. We used homeostasis model assessment (HOMA) 2\%B and HOMA2\%S as estimates of $\beta$-cell function and insulin sensitivity, respectively. HOMA2\%B and HOMA2\%S were calculated from fasting plasma glucose and fasting serum C-peptide using the HOMA2 model calculator

(http://www.dtu.ox.ac.uk/homa) [12]. The disposition index based on HOMA2 method, which reflects the overall homeostatic ability of an individual, was also calculated by multiplying HOMA2\%S by HOMA2\%B (normal value: 1.0) [13]. The difference of each clinical variable between the baseline and after 16 weeks was calculated by subtracting the value at the baseline from that at 16 weeks.

\subsection{Statistical Analysis}

All statistical analyses were performed using SPSS for Windows, Version 11.0 (SPSS, Chicago, IL, USA). Continuous variables are expressed as mean \pm standard deviation (SD) or median (interquartile range). Differences of the clinical variables between the baseline and 16 weeks were tested with the Wilcoxon signed-rank test. Correlations between the changes in each variable were calculated with univariate linear regression analysis. Multivariate linear regression analysis was used to evaluate the relative contribution of $\beta$-cell function and insulin sensitivity to reduction in HbA1c. All $p$ values were two-sided. A $p$ value $<0.05$ was considered to be statistically significant.

\section{RESULTS}

Baseline characteristics of the study patients are shown in Table 1 . Most patients were men (85.0\%). The mean age and body mass index (BMI) were 49.1 years and $26.4 \mathrm{~kg} / \mathrm{m}^{2}$, respectively.

Effects of metformin on clinical variables related to glycemic control were shown in Table 2. After 16 weeks, HbA1c decreased from $9.53 \% \pm 2.19 \%$ to $6.58 \% \pm$ 
Table 1. Baseline characteristics of the study patients.

\begin{tabular}{lc}
\hline Variable & \\
\hline $\mathrm{n}$ & 20 \\
Men (\%) & $17(85.0)$ \\
Age (years) & $49.1 \pm 10.1$ \\
Body weight (kg) & $74.1 \pm 13.6$ \\
Body mass index (kg/m²) & $26.4 \pm 5.2$ \\
Systolic blood pressure (mmHg) & $122 \pm 34$ \\
Diastolic blood pressure (mmHg) & $83 \pm 14$ \\
Fasting plasma glucose (mmol/l)) & $10.8 \pm 4.0$ \\
HbA1c (\%) & $9.5 \pm 2.2$ \\
Total cholesterol (mmol/l) & $5.65 \pm 0.98$ \\
HDL-cholesterol (mmol/l) & $1.24 \pm 0.27$ \\
LDL-cholesterol (mmol/l) & $3.50 \pm 0.79$ \\
Triglyceride (mmol/l) & $1.57(1.01$ - 2.42) \\
\hline
\end{tabular}

Data are mean \pm SD or median (interquartile range).

Table 2. Changes in clinical variables related to glycemic control during 16 weeks.

\begin{tabular}{lccc}
\hline Variable & Baseline & After 16 weeks & $p$-value \\
\hline $\begin{array}{l}\text { Body weight }(\mathrm{kg}) \\
\begin{array}{l}\text { Body mass index } \\
\left.\text { (kg/m }{ }^{2}\right)\end{array}\end{array}$ & $74.1 \pm 13.6$ & $71.8 \pm 11.7$ & 0.032 \\
$\begin{array}{l}\text { Fasting plasma } \\
\text { glucose (mmol/l) }\end{array}$ & $10.8 \pm 4.0$ & $6.7 \pm 0.8$ & $<0.001$ \\
HbA1c (\%) & $9.5 \pm 2.2$ & $6.6 \pm 0.9$ & $<0.001$ \\
$\begin{array}{l}\text { Fasting C-peptide } \\
\text { (mmol/l) }\end{array}$ & $0.66(0.53-0.99)$ & $0.62(0.48-0.75)$ & 0.156 \\
HOMA2\%B & $38.8(20.1-63.1)$ & $68.8(53.9-85.8)$ & $<0.001$ \\
HOMA2\%S & $50.2(38.9-66.4)$ & $67.1(59.3-89.4)$ & 0.004 \\
\hline
\end{tabular}

Differences between baseline and after 16 weeks were tested with Wicoxon signed rank test. HOMA: homeostasis model assessment.

$0.91 \%(p<0.001)$. FPG also decreased from $10.84 \pm$ $4.02 \mathrm{mmol} / \mathrm{l}$ to $6.67 \pm 0.82 \mathrm{mmol} / \mathrm{l}(p<0.001)$. Although fasting serum $\mathrm{C}$-peptide did not significantly change, we found significant increase in both HOMA2\%B (38.8\% to $68.8 \%, p<0.001)$ and HOMA2\%S $(50.2 \%$ to $67.1 \%, p<$ 0.004). Figure 1 illustrates a graphic representation of the relationship between HOMA2\%S and HOMA2\%B based on longitudinal measurements of both parameters. Visual examination of the graph indicated that most patients experienced the improvement in $\beta$-cell function relative to insulin sensitivity, as shown by upward and rightward shifts of their dots after 16 weeks. This was further corroborated by a significant increase in the disposition index calculated from HOMA2 estimates from $0.20(0.10-0.31)$ at baseline to $0.48(0.40-0.59)$ after 16 weeks $(p<0.001)$.

To explore baseline variables related to HbA1c-lower-

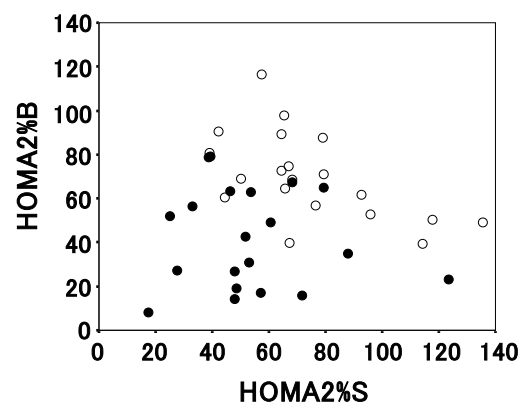

Figure 1. Relationship between HOMA2\%S and HOMA2\%B at baseline (closed circles) and 16 weeks (open circles).

ing effect of metformin, we examined the correlations between the change in HbA1c and the baseline values of clinical variables (Table 3 ). Neither baseline body weight $(r=0.260, p=0.267)$ nor BMI $(r=0.234, p=0.321)$ was correlated with the change in HbA1c. We found strong correlation between baseline HbA1c and the change in HbA1c $(r=-912, p<0.001)$. Although baseline HOMA2\%B was significantly correlated with the change in HbA1c ( $r=0.562, p=0.010)$, baseline HOMA2\%S was not significantly correlated with the change in HbA1c $(r=0.396, p<0.084)$.

To know the variables associated with the change in HbA1c, we examined the correlations between the change in $\mathrm{HbA} 1 \mathrm{c}$ and the change in other clinical variables (Table 4). The change in BMI was not correlated with the change in HbA1c $(r=-0.286, p=0.221)$. We found strong correlation between the change in

HOMA2\%B and the change in HbA1c $(r=-0.866, p<$ 0.001 , Figure 2(a)). However, the change in

HOMA2\%S was not significantly correlated with the change in HbA1c $(r=-0.264, p=0.260$, Figure 2(b)). Multivariate linear regression analysis with the change in HbA1c as a dependent variable showed that the change in HOMA2\%B, but not HOMA2\%S was a significant independent variable in the model (Table 5). In addition, adjusted coefficient of determination $\left(R^{2}\right)$ indicated that the change in HOMA2\%B and HOMA2\%S explained $73.0 \%$ of the variance of the change in HbA1c.

\section{DISCUSSION}

We found that metformin improved $\beta$-cell function and insulin sensitivity in newly diagnosed patients with Type 2 diabetes. We also found that improved $\beta$-cell function rather than increased insulin sensitivity was associated with reduction in HbA1c.

Several studies have previously demonstrated that metfromin improves $\beta$-cell function and insulin sensitivity in patients with newly diagnosed Type 2 diabetes. Nagi et al. showed that metforim treatment for 12 weeks significantly improved metabolic clearance rate, which is 
Table 3. Relationship between change in HbA1c and baseline clinical variables.

\begin{tabular}{lcc}
\hline Variable & $r$ & $p$-value \\
\hline Age (years) & -0.231 & 0.326 \\
Body weight $(\mathrm{kg})$ & 0.260 & 0.267 \\
Body mass index $\left(\mathrm{kg} / \mathrm{m}^{2}\right)$ & 0.234 & 0.321 \\
Fasting plasma glucose $(\mathrm{mmol} / \mathrm{l})$ & -0.708 & $<0.001$ \\
HbA1c $(\%)$ & -0.912 & $<0.001$ \\
Fasting C-peptide $(\mathrm{mmol} / \mathrm{l})$ & -0.060 & 0.802 \\
HOMA2\%B & 0.562 & 0.010 \\
HOMA2\%S & 0.396 & 0.084 \\
\hline
\end{tabular}

Correlations were tested with univariate linear regression analysis. HOMA: homeostasis model assessment.

Table 4. Relationship between change in HbA1c and change in other clinical variables.

\begin{tabular}{lcc}
\hline Variable & $r$ & $p$-value \\
\hline$\Delta$ Body weight $(\mathrm{kg})$ & -0.266 & 0.257 \\
$\Delta$ Body mass index $\left(\mathrm{kg} / \mathrm{m}^{2}\right)$ & -0.286 & 0.221 \\
$\Delta$ Fasting plasma glucose $(\mathrm{mmol} / \mathrm{l})$ & 0.739 & $<0.001$ \\
$\Delta$ Fasting C-peptide $(\mathrm{mmol} / \mathrm{l})$ & 0.014 & 0.952 \\
$\Delta$ HOMA2\%B & -0.866 & $<0.001$ \\
$\Delta$ HOMA2\%S & -0.264 & 0.260 \\
\hline
\end{tabular}

Correlations were tested with linear regression analysis. HOMA: homeostasis model assessment. $\Delta$ means the difference between baseline and 16 weeks.

Table 5. Multivariate linear regression analysis with change in HbA1c as a dependent variable.

\begin{tabular}{ccccc}
\hline 0 & Standardized $\beta$ & $\mathrm{t}$ & $p$-value & Adjusted $R^{2}$ \\
\hline HOMA2\%B & -0.847 & -6.958 & $<0.001$ & 0.730 \\
HOMA2\%S & -0.093 & -0.763 & 0.456 & \\
\hline
\end{tabular}

HOMA: homeostasis model assessment. $R^{2}$ : coefficient of determination.
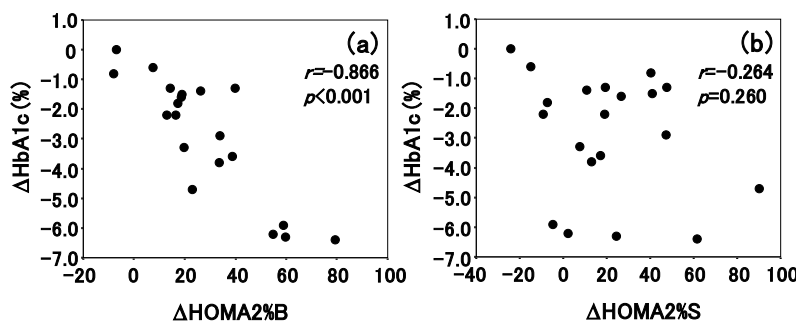

Figure 2. Correlations between change in HOMA2\%B ( $\triangle \mathrm{HOMA} 2 \% \mathrm{~B}$, panel (a)) or change in HOMA2\%S $(\triangle \mathrm{HOMA} 2 \% \mathrm{~S}$, panel (b)) and the change in HbA1c $(\Delta \mathrm{HbA} 1 \mathrm{c})$ during 16 weeks treatment. Correlations were tested with univariate linear regression analysis.

a measure of peripheral insulin sensitivity, and $\beta$-cell function estimated from HOMA method [14]. In the UKPDS16 [7], metformin treatment for a year improved $\beta$-cell function and insulin sensitivity in patients with newly diagnosed Type 2 diabetes. Moreover, metformin improved $\beta$-cell function and insulin sensitivity in recently diagnosed Type 2 diabetes during the first six months of the ADOPT (A Diabetes Outcome Progression Trial) Study [15]. Because the relationship between insulin sensitivity and $\beta$-cell function is non-linear and best described by a hyperbolic function, the product of insulin sensitivity and $\beta$-cell function (the disposition index) provide a true measure of $\beta$-cell function, rather insulin sensitivity or $\beta$-cell function in isolation [16]. Interestingly, the plots in Figure 1 showed that the dots depicting HOMA2\%S versus HOMA2\%B shifted upward and rightward, suggesting that metformin improved the disposition index. This is further corroborated by the finding that the disposition index calculated from

HOMA2\%B and HOMA2\%S increased from 0.20 at baseline to 0.48 after 16 weeks $(p<0.001)$ ). Consistent with this, metformin improved the disposition index in recently diagnosed Type 2 diabetes in the ADOPT Study [17].

However, none of the studies mentioned above examined the relative contribution of improved $\beta$-cell function and increased insulin sensitivity to reduction in HbA1c in newly diagnosed Type 2 diabetic patients treated with metformin. Although we found strong correlation between the change in $\beta$-cell function and the change in HbA1c, we did not find a significant correlation between the change in insulin sensitivity and the reduction in HbA1c (Table 4, Figure 2), suggesting that improved $\beta$-cell function rather than insulin sensitivity contributes more to reduction in HbA1c. This is further corroborated by the results of the multivariate regression analysis indicating that change in HOMA2\%B but not that in HOMA2\%S was a significant independent variable in the model (Table 5). Therefore, improved $\beta$-cell function rather than increased insulin sensitivity is associated with reduction in $\mathrm{HbA1c}$ in patients with newly diagnosed type diabetes treated with metformin.

Because metformin does not directly stimulate insulin secretion, it is difficult to know the exact mechanisms whereby reduction in HbA1c with metformin treatment is associated with improved $\beta$-cell function rather than insulin sensitivity. However, several studies suggest that $\beta$-cell function rather than insulin sensitivity is a major determinant of HbA1c in patients with Type 2 diabetes. First, in the first six years of the UKPDS, the deterioration of HbA1c was associated with progressive loss of $\beta$-cell function but not with insulin sensitivity [7]. Next, in the 4-year follow-up of the ADOPT Study, although insulin sensitivity progressively improved in patients treated with metformin, the increase in HbA1c was associated with a progressive decline in $\beta$-cell function [15]. Finally, Monnier et al. showed that, although the role of 
insulin sensitivity is not negligible, $\beta$-cell function is the major determinant of HbA1c in Type 2 diabetic patients [18]. On the other hand, previous studies have showed that $\beta$-cell function was improved when fasting plasma glucose levels are lowered irrespective of the mode of treatment [19]. Consistent with this, we found strong correlation between reduction in FPG and the change in HOMA2\%B ( $r=-0.812, p<0.001$, data not shown). Because the chief glucose-lowering effect of metformin is believed to reduce FPG through suppression of endogenous glucose production by the liver [20], metformin may improve $\beta$-cell function through reduction in FPG.

The main limitation of the present study is its retrospective design without a parallel control group, which prevents us drawing conclusions about causality.

Another limitation is that we chose to obtain measures of $\beta$-cell function and insulin sensitivity, namely

HOMA2\%B and HOMA2\%S, that were the most practical to apply in routine clinical setting. This means that we did not use more sophisticated and precise measures of $\beta$-cell function and insulin sensitivity. However, we do not believe that this severely limits our findings because the HOMA method has been validated against a variety of physiological methods [21].

In conclusion, our data demonstrate that improved $\beta$-cell function rather than increased insulin sensitivity is associated with reduction in HbA1c in newly diagnosed Type 2 diabetic patients treated metformin. These results suggest that metformin reduces HbA1c chiefly through improved $\beta$-cell function rather than increased insulin sensitivity in patients with newly diagnosed Type 2 diabetes.

\section{ACKNOWLEDGEMENTS}

The authors declare no conflict of interest relevant to this manuscript.

\section{REFERENCES}

[1] UK Prospective Diabetes Study (UKPDS) Group. (1998) Effect of intensive blood glucose control with metformin on complications in overweight patients with Type 2 diabetes. (UKPDS34). Lancet, 352, 854-865. http://dx.doi.org/10.1016/S0140-6736(98)07037-8

[2] UK Prospective Diabetes Study (UKPDS) Group. (1990) UK Prospective Diabetes Study 7: Response of fasting plasma glucose to diet therapy in newly presenting Type II diabetic patients. Metabolism, 39, 905-912. http://dx.doi.org/10.1016/0026-0495(90)90299-R

[3] Chan, J.C.N., Deerochanawong, C., Shera, A.S., Yoon, K.H., Adam, J.M.F., Binh, T.V., Chan, S.P., Fernando, R.E., Horn, L.C., Khue, N.T., Litonjua, A.D., Soegondo, S. and Zimmet, P. (2007) Role of metformin in the initiation of pharmacotherapy for Type 2 diabetes: An AsianPacific perspective. Diabetes Research and Clinical Pra- ctice, 75, 255-266.

http://dx.doi.org/10.1016/j.diabres.2006.06.023

[4] Inzucchi, S.E., Bergenstal, R.M., Buse, J.B., Diamant, M., Ferrannini, E., Nauck, M., Peters, A.L., Tsapas, A., Wender, R. and Matthews, D.R. (2012) Management of hyperglycemia in Type 2 diabetes: A patient-centered approach. Diabetes Care, 35, 1364-1379.

[5] Sumitani, S., Morita, S., Utsu, Y., Mukai, K., Miki, S., Sato, B., Nakamura, H. and Kasayama, S. (2012) Effectiveness of metformin and lifestyle interventions as an initial treatment in Japanese patients with newly diagnosed Type 2 diabetes: A prospective observational study. Journal of Medical Investigation, 59, 166-173.

http://dx.doi.org/10.2152/jmi.59.166

[6] Rudenski, A.S., Hadden, D.R., Atkinson, A.B., Kennedy, L., Matthews, D.R., Merrett, J.D. and Turner, R.C. (1988) Natural history of pancreatic B-cell function in Type 2 diabetes mellitus studied over six years by homeostasis model assessment. Diabetic Medicine, 5, 36-41. http://dx.doi.org/10.1111/j.1464-5491.1988.tb00938.x

[7] UK Prospective Diabetes Study (UKPDS) Group (1995) UK Prospective Diabetes Study 16: Overview of 6 years' therapy of Type II diabetes: A progressive disease. Diabetes, 44, 1249-1258. http://dx.doi.org/10.2337/diab.44.11.1249

[8] DeFronzo, R.A. (2009) From the triumvirate to the ominous octet: A new paradigm for the treatment of Type 2 diabetes.Diabetes, 58, 773-795. http://dx.doi.org/10.2337/db09-9028

[9] World Health Organization (1999) Definition, diagnosis and classification of diabetes mellitus and its complications. Report of a WHO consultation. Part 1: Diagnosis and classification of diabetes mellitus. Geneva, World Health Organization.

[10] The Committee of Japan Diabetic Society on the diagnostic criteria of diabetes mellitus (2010) Report of the Committee on the classification and diagnostic criteria of diabetes mellitus. J Diabetes Invest, 1, 212-228.

[11] Friedewald, W.T., Levy, R.I. and Friedrickson, D.S. (1972) Estimation of the concentration of low-density lipoprotein cholesterol in plasma, without use of the preparative ultracentrifuge. Clinical Chemistry, 18, 499-502.

[12] Levy, J.C., Matthews, D.R. and Hermans, M.P. (1998) Correct homeostasis model assessment (HOMA) evaluation uses the computer program. Diabetes Care, 21, 21912192. http://dx.doi.org/10.2337/diacare.21.12.2191

[13] Caumo, A., Perseghin, G., Brunani, A. and Luzi, L. (2006) New insights on the simultaneous assessment of insulin sensitivity and $\beta$-cell function with the HOMA2 method. Diabetes Care, 29, 2733-2734. http://dx.doi.org/10.2337/dc06-0070

[14] Nagi, D.K. and Yudkin, J.S. (1993) Effects of metformin on insulin resistance, risk factors for cardiovascular disease, and plasminogen activator inhibitor in NIDDM subjects. Diabetes Care, 16, 621-629. http://dx.doi.org/10.2337/diacare.16.4.621

[15] The ADOPT Study Group (2006) Glycemic durability of 
rosiglitazone, metformin, or glyburide monotherapy. The New England Journal of Medicine, 355, 2427-2443. http://dx.doi.org/10.1056/NEJMoa066224

[16] Kahn, S.E. (2003) The relative contributions of insulin resistance and beta-cell dysfunction to the pathophysiology of Type 2 diabetes. Diabetologia, 46, 3-19.

[17] The ADOPT Study Group (2011) Effects of rosiglitazone, glyburide, and metformin on b-cell function and insulin sensitivity in ADOPT. Diabetes, 60, 1552-1560. http://dx.doi.org/10.2337/db10-1392

[18] Monnier, L., Colette, C., Thuan, J.F. and Lapinsk, H. (2006) Insulin secretion and sensitivity as determinants of HbA1c in Type 2 diabetes. European Journal of Clinical Investigation, 36, 231-235. http://dx.doi.org/10.1111/j.1365-2362.2006.01623.x
[19] Kosaka, K., Kuzuya, T., Akanuma, Y. and Hagura, R. (1980) Increase in insulin response after treatment of overt maturity onset diabetes mellitus is independent of the mode of treatment. Diabetologia, 18, 23-28. http://dx.doi.org/10.1007/BF01228297

[20] Inzucchi, S.E., Maggs, D.G., Spollett, G.R., Page, S.L., Rife, F.S., Walton, V. and Shulman, G.I. (1998) Efficacy and metabolic effects of metformin and troglitazone in Type II diabetes mellitus. The New England Journal of Medicine, 338, 867-872. http://dx.doi.org/10.1056/NEJM199803263381303

[21] Wallace, T.M., Levy, J.C. and Matthews, D.R. (2004) Use and abuse of HOMA modeling. Diabetes Care, 27, 14871495. http://dx.doi.org/10.2337/diacare.27.6.1487 